\title{
Development and characterization of an integrated silicon micro flow cytometer
}

\author{
R. Bernini • E. De Nuccio • F. Brescia • A. Minardo • \\ L. Zeni • P. M. Sarro • R. Palumbo • M. R. Scarfi
}

Published online: 4 November 2006

(C) Springer-Verlag 2006

Regrettably, the legends of Figs. 4 and 5 were mistakenly interchanged. The corrected figures with the corresponding legends are given below.

Fig. 4 Schematic representation of the experimental setup used for characterization of the integrated micro flow cytometer

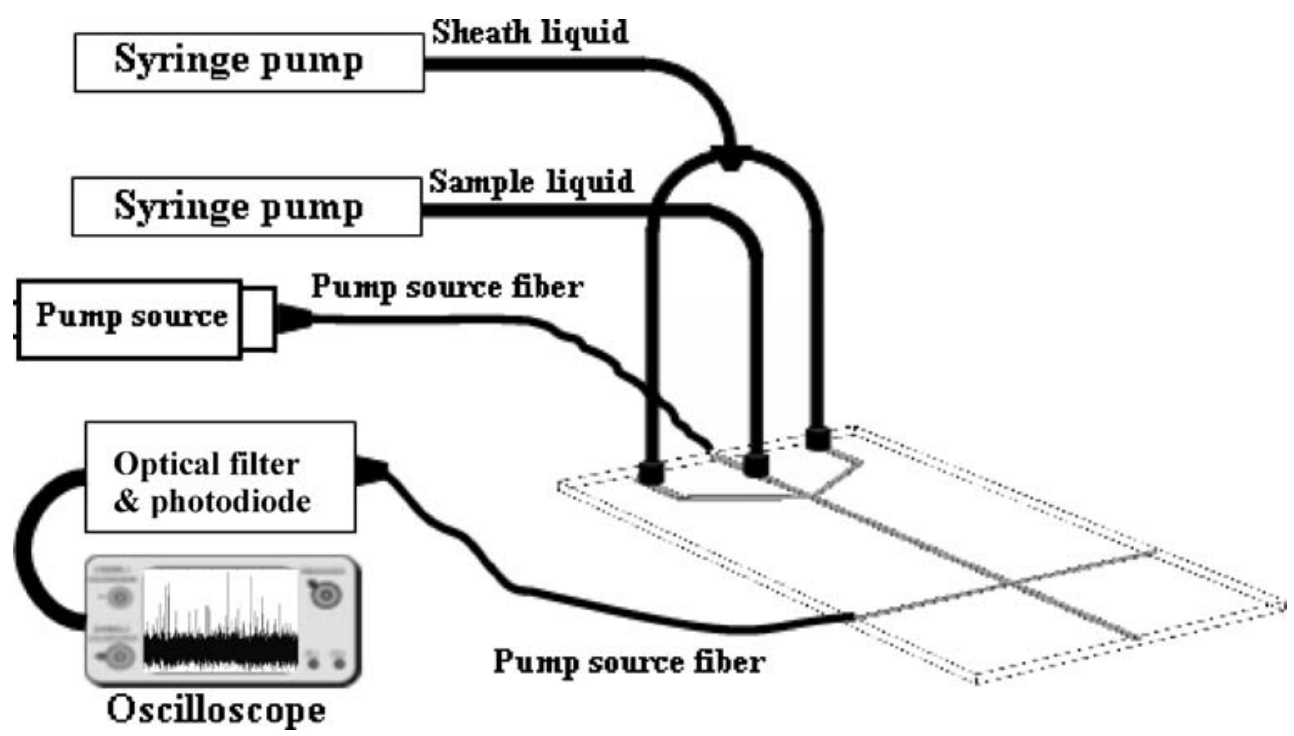

The online version of the original article can be found at http://dx.doi. org/10.1007/s00216-006-0623-y.

R. Bernini $(\bowtie) \cdot$ F. Brescia $\cdot$ M. R. Scarfi IREA-CNR,

Via Diocleziano 328,

80124 Napoli, Italy

e-mail: bernini.r@irea.cnr.it

E. De Nuccio $\cdot$ A. Minardo $\cdot$ L. Zeni

DII, Seconda Università di Napoli,

Via Roma 29,

81031 Aversa, Italy

P. M. Sarro

ECTM-DIMES, TUDelft.,

Feldmannweg 17,

2600 GB Delft, The Netherlands

R. Palumbo

IBB-CNR,

Via Mezzocannone 16,

80134 Napoli, Italy

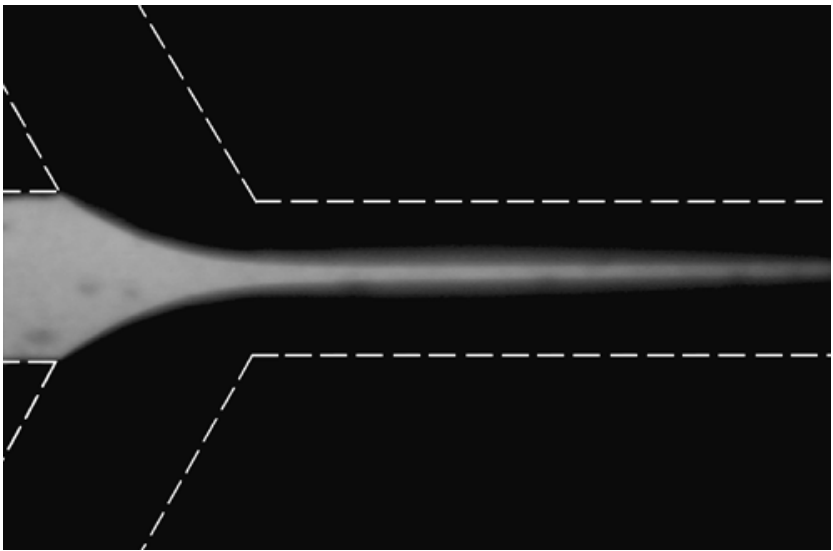

Fig. 5 The hydrodynamic focusing effect in the micro flow cytometer. The width of the focused stream is approximately $24 \mu \mathrm{m}$ 